presenting symptom is a matter of choice for the patient, as this case illustrates. Of the multiple symptoms she had, yellow skin was chosen as the presenting feature. Although the general practitioner realised that the yellow tinge of her skin sparing the sclerae was probably not jaundice, he did request liver function tests to exclude this condition. The chemical pathology staff were alert enough to recognise the possibility of hypercarotenaemia and underlying hypothyroidism and to instigate the necessary tests to prove it.

It is acknowledged that hypothyroidism confers a yellow tint to the skin in many patients, especially if the palms and soles are examined. ${ }^{1}$ However, we feel that yellowing of the whole body skin as a sole presenting feature of hypothyroidism must be extremely rare as other signs and symptoms usually dominate the clinical picture. In this case the patient did admit having symptoms suggestive of thyroid hormone deficiency for 18 months, a duration long enough perhaps to increase the chance of development of hypercarotenaemia to such a degree.

It has long been noted that sera from cases of myxoedema and cretinism are characteristically of a deeper orange-yellow colour than normal due to increased concentration of the carotenoid pigments that are carried by specific lipoproteins. ${ }^{12}$ Furthermore, administration of $\beta$-carotene to hypothyroid patients results in a sharp increase and delayed clearance of its plasma concentration compared with normal subjects. ${ }^{3}$ The hypercarotenaemia of myxoedema is thought to be due to reduced conversion of carotenoids to retinol, and it has been suggested that vitamin A deficiency may ensue as a result, causing the dry scaly skin typical of hypothyroid patients. ${ }^{4}$ The concentration of plasma carotene is greatly influenced by dietary intake but our patient denied excessive consumption of carotene-rich foods. High concentrations are also found in hyperlipidaemia associated with diabetes mellitus and chronic renal failure. ${ }^{5}$

This patient represents an excellent case example from the chemical pathology point of view, as she displayed all the biochemical abnormalities describable in hypothyroidism, which were successfully corrected by thyroxine replacement. The main message from this case is that the patient whose yellow skin is not due to jaundice is worth investigating for hypercarotenaemia and possible hypothyroidism.

1 Rivlin RS. Vitamin metabolism. In: Werner SC, Ingbar $\mathrm{SH}$, eds. The thyroid a fundamental and clinical text. 4 th edn. New York: Harper and Row, 1978:878-83.

2 Walton KW, Dorothy A, Campbell A, Tonks EL. The significance of alterations in serum lipids in thyroid dyssignificance of alterations in serum lipids in thyroid dysfunction. 1. The relation between serum lipoproteins, carotenoids and vitamin A in hypoth

3 Mandal SK, Dastidar AG. Carotene and retinol levels in the diagnosis of hypothyroidism. fournal of the Association of Physicians of India 1985;33:654-5.

4 Mandal SK, Dastidar AG. Hypor cyroridism as a possible cause of vitamin A deficiency. I Indian Med Assoc 1985;83:339-40.

5 McMurray W, Gowenlock AH. Vitamins. In: Gowenlock AH, McMurray JR, McLauchlan DM, eds. Varley's practical clinical biochemistry. 6th edn. London: Heinmann Medical Books, 1988:894-930.

\title{
Paget's disease of the breast in a man without underlying breast carcinoma
}

\author{
S T O'Sullivan, G T McGreal, A Lyons, L Burke, J G Geoghegan, M P Brady
}

\author{
University \\ Department of \\ Surgery, Cork \\ Regional Hospital and \\ University College, \\ Cork, Ireland \\ $S$ T O'Sullivan \\ G T McGreal \\ A Lyons \\ J G Geoghegan \\ M P Brady \\ University \\ Department of \\ Pathology \\ L Burke \\ Correspondence to: \\ S T O'Sullivan, 28 \\ Rossbrook Model Farm \\ Road, Cork, Ireland \\ Accepted for publication \\ 24 March 1994
}

\begin{abstract}
A case of histologically confirmed Paget's disease of the breast in a 72 year old man, without underlying breast carcinoma, is reported. This report raises questions about the pathogenesis of this condition and suggests that Paget's disease is an independent, intraepidermal carcinoma rather than a direct extension of intraductal carcinoma of the breast to the nipple and areola.
\end{abstract}

$(f$ Clin Pathol 1994;47:851-852)

About $1 \%$ of all breast carcinomas occur in men, ${ }^{12}$ and $1-5 \%$ of all cases of breast carci- noma present as Paget's disease. ${ }^{3}$ Paget's disease of the male breast is therefore exceptionally rare. About 55 cases of Paget's disease of the male breast have been reported to date. All of these were associated with an underlying breast carcinoma. However, published reviews of the condition by Serour, ${ }^{4}$ Crichlow and Czernobilsky, ${ }^{2}$ and Satiani ${ }^{5}$ rejected many of these cases because of a lack of histopathological evidence.

Paget's disease without an underlying breast carcinoma has been reported before, ${ }^{36}$ although not in men. We report a case of histologically confirmed Paget's disease of the breast occurring in a 72 year old Irish man in whom there was no associated breast carcinoma. 


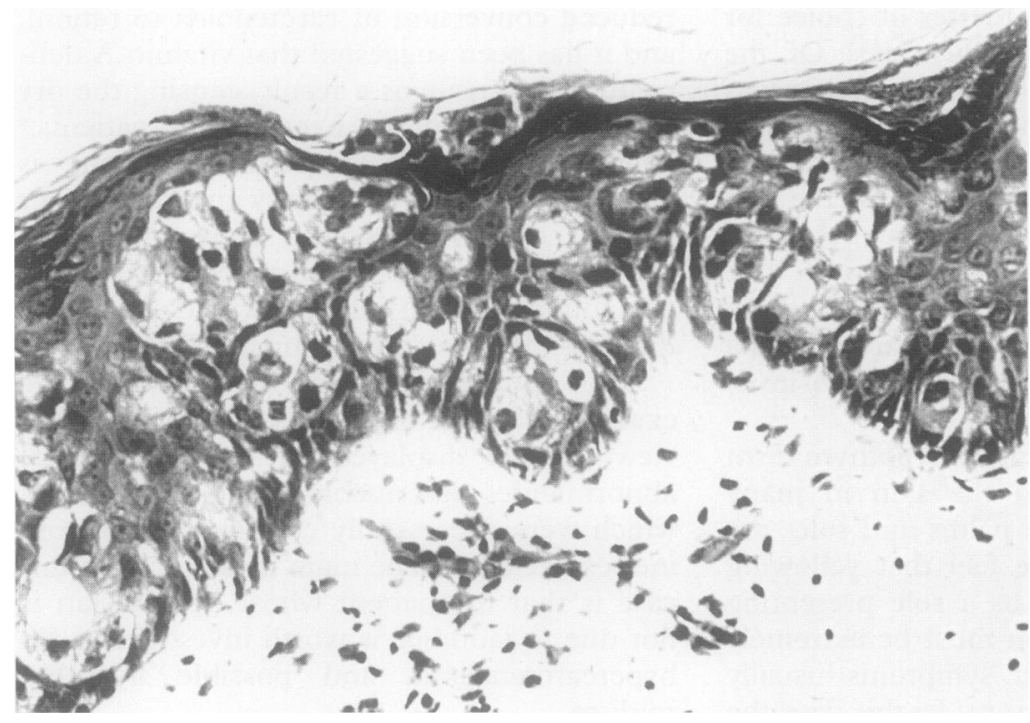

Photomicrograph of male areolar skin showing typical Paget's cells distributed throughout the epidermis (haematoxylin and eosin stain).

\section{Case report}

A 72 year old man presented with a left breast mass which had been present for four months. This was associated with an area of periareolar erythema which he claimed had been present for many years. There was no family history of breast carcinoma. The patient was in otherwise good physical condition and was taking no medication. Examination of the left breast revealed a nonretracted nipple with surrounding eczematous change. A non-tender mobile mass measuring $2 \times 2 \mathrm{~cm}$ was identified in the inner lower quadrant, without skin tethering or adherence to deep tissues. There was no evidence of nipple discharge or lymphadenopathy. The right breast was normal. Laboratory investigations, including complete blood count and full biochemical profile were normal, as was a chest radiograph. Excisional biopsy of the areolar area was performed and histopathological examination of the specimen revealed Paget's disease of the breast. The patient then proceeded to simple mastectomy. His postoperative course was uneventful and he remained well at follow up nine months later, at the time of writing.

\section{Histopathological findings}

The mastectomy specimen comprised a triangular ellipse of skin measuring $13 \times 10.5 \mathrm{~cm}$, including nipple and areola, which showed an area of crusting extending to the adjacent skin. Serial slicing did not show an underlying carcinoma apart from two circumscribed fatty lesions. No lymph nodes were found. Microscopic examination showed Paget's disease but no underlying carcinoma was identi- fied. The two fatty lesions were confirmed as lipomas.

The areolar biopsy specimen showed hyperkeratosis, papillomatosis, and evidence of underlying chronic inflammation.

Sections of the eczematous skin revealed numerous large pleomorphic cells with dark nuclei and foamy or clear cytoplasm distributed throughout the epidermis (figure). Periodic acid Schiff stain showed intracellular diastase resistant material. Immunohistochemistry demonstrated positive staining for epithelial membrane antigen (EMA) and anti-human cytokeratin (CAM 5.2), but was negative for $\mathrm{S} 100$ and HMB 45.

\section{Discussion}

The accurate pathogenesis of Paget's disease of the breast remains to be established. Muir postulated that areolar and nipple changes occur as a result of direct extension, via the ducts, of cells from an underlying carcinoma. ${ }^{7}$ This remains the most widely accepted theory of pathogenesis for the disease. However, our finding of a case of histologically confirmed Paget's disease of the breast without an associated carcinoma is at variance with this theory and instead suggests that Paget's disease is an independent, intraepithelial carcinoma. Although the characteristic nipple and areolar changes of Paget's disease may precede the development of clinically obvious cancer by several years, ${ }^{5}$ in this case a thorough search failed to demonstrate any histopathological features of breast carcinoma in our patient. Others support the view that the malignant cells in Paget's disease originate from eccrine or apocrine glands in the area. ${ }^{8}$ This view is supported by certain histochemical and electron microscopic findings, as described in detail by Ho. ${ }^{8}$ This report casts further doubt on the traditional opinion of the origin of Paget's disease and lends further support to the theory that Paget's disease is, in fact, a separate breast neoplasm from the carcinoma with which it is frequently associated.

\footnotetext{
1 Nehme AE. Paget's disease of the male breast: a collective review and a case report. Am Surg 1976;42:289-95. 2 Crichlow RN, Czernobilsky B. Paget's disease of the male breast. Cancer 1969;24:1033-40.

3 Ashikari R, Park K, Huvos AG, Urban JA. Paget's diseas of breast. Cancer 1970;26:680-5.

4 Serour F, Birkenfeld S, Amsterdam E, Treshchan O Krispin M. Paget's disease of the male breast. Cancer 1988;62:601-5.

5 Satiani B, Powell RW, Mathews WH. Paget's disease of the male breast. Arch Surg 1977;112:587-92.

6 Paone JF, Baker RR. Pathogenesis and treatment of Paget's disease of the breast. Cancer 1981;48:825-9.

7 Muir R. Further observations on Paget's disease of the nipple. F Pathol Bacteriol 1939;49:299-312.

8 Ho TCN, St Jacques M, Schopflocher P. Pigmented Paget's disease of the male breast. $₹$ Am Acad Dermatol 1990;23:338-41.
} 